Resenha por: Renata Rothbarth ${ }^{1}$

\title{
REGULAÇÃO DE MEDICAMENTOS NO MUNDO GLOBALIZADO
}

Fernando Aith, Sueli Dallari (orgs.), Cepedisa, 2014

${ }^{1}$ Núcleo de Pesquisa em Direito Sanitário da Universidade de São Paulo. São Paulo/SP, Brasil.

Correspondência: Renata Rothbarth. E-mail: renata.rothbarth@hotmail.com.

Recebido em: 09/06/2015. 
A publicação Regulação de medicamentos no mundo globalizado apresenta aos leitores uma fértil discussão a respeito de conflitos e questões pertinentes à regulação de medicamentos no mundo atual.

Composta por 11 artigos, a publicação apresenta os resultados de uma pesquisa sobre a regulação de medicamentos em diferentes países, como Estados Unidos, França, Índia e Brasil, realizada pelo Núcleo de Pesquisa em Direito Sanitário da Universidade de São Paulo (NAP-DISA/USP) e pelo Centro de Estudos e Pesquisas de Direito Sanitário (Cepedisa). O estudo contou com a participação de pesquisadores de todos os países investigados.

Os artigos que compõem a publicação evidenciam importantes elementos que permeiam a regulação farmacêutica no mundo globalizado e analisam a qualidade e a efetividade, em escala nacional e internacional, das normas que atualmente regulamentam a fabricação, dispensação e comercialização de medicamentos. O artigo Política de regulação de drogas e medicamentos no Brasil: panorama normativo e institucional ${ }^{1}$ serviu como marco teórico da obra. Dentre as principais conclusões dos autores do texto, podemos citar: (a) a constatação de um arcabouço normativo demasiadamente fragmentado no cenário brasileiro; (b) a ausência de políticas públicas que integrem a questão farmacêutica ao Sistema Único de Saúde; (c) a burocracia excessiva e a confusão de competências administrativas no âmbito das três esferas de governo (federal, estadual e municipal); e ainda (d) o desacordo entre a política regulatória nacional e as tendências internacionais.

A partir desse posicionamento, os colaboradores internacionais buscaram estabelecer paralelos entre o contexto brasileiro e o de seus países de origem. $\mathrm{O}$ artigo de Jytte Lyngvig ${ }^{2}$ apresenta um apanhado histórico do sistema regulatório europeu desde a década de 1990 até os dias atuais, com destaque para as conquistas perceptíveis após a criação da Rede Europeia de Regulação de Medicamentos. No sentido de "aumentar a harmonização do processo regulatório de medicamentos no Brasil"', a autora apresenta sugestões para otimizar o processo de desenvolvimento e aprovação de novos medicamentos.

Nesse diapasão, o artigo do professor Jérome Peigné $e^{4}$ joga luz sobre o sistema de farmacovigilância de seu país - a França. Com base nos dispositivos do Código

\footnotetext{
${ }^{1}$ AITH, Fernando M. A.; CUNHA, Ana Carolina Navarrete M. F. da; CASTELLARO, Felipe Angel B.; SOARES, Darnise Francinne Lopes; DALLARI, Sueli Gandolfi. Política de regulação de drogas e medicamentos no Brasil: panorama normativo e institucional. In: AITH, Fernando; DALLARI, Sueli Gandolfi (Orgs.). Regulação de medicamentos no mundo globalizado. 1. ed. São Paulo: CEPEDISA, 2014. p. 459-556.

${ }^{2}$ Vice-Presidente sênior e diretora administrativa da Drug Information Association (DIA) para a Europa, Oriente Médio e África.

${ }^{3}$ LYNGVIG, Jytte. Uma grande abelha que voa ou como o desenvolvimento da Rede Europeia de Regulação de Medicamentos pode inspirar as considerações para reforma do registro de medicamentos no Brasil. In: AITH, Fernando; DALLARI, Sueli Gandolfi (Orgs.). op. cit., p. 47-63.

${ }^{4}$ PEIGNÉ, Jérôme. Mudanças no sistema francês de farmacovigilância (monitoramento de medicamentos): a crescente influência do direito da União Europeia. In: AITH, Fernando; DALLARI, Sueli Gandolfi (Orgs.). op. cit., p. 81-100.
} 
de Saúde Pública francês, a Agência Nacional de Medicamentos e Produtos de Saúde é a responsável por detectar, naquele país, condutas abusivas, realizar avaliações científicas, permitir ou suspender a comercialização de um determinado fármaco e "coletar informações relevantes para o monitoramento de medicamentos, incluindo seus efeitos colaterais" ${ }^{\prime \prime}$. Na opinião do autor, o sistema francês ainda apresenta algumas deficiências técnicas e, assim como constatado em relação ao Brasil, a França também sofre com a falta de uma política integrada de medicamentos.

A segunda contribuição francesa para a publicação versa sobre o combate aos chamados "conflitos de interesse" na área de saúde. Em Os conflitos de interesse no direito sanitário francês ${ }^{6}$, a autora Anne Laude disseca os mecanismos legais que foram gradualmente normatizados na França, com vistas à garantia de transparência e probidade na tomada de decisões em assuntos de saúde pública. A estratégia mais recente nesse sentido é o Sunshine Act à la Française, uma norma inspirada no ordenamento norte-americano que obriga todas as empresas do ramo de saúde a comunicarem eletronicamente, junto à Secretaria de Saúde e de Serviços Humanos da França, todos os pagamentos ou benefícios superiores a 10 euros pagos a profissionais de saúde, além de parentes ou amigos destes e hospitais universitários.

Outra contribuição francesa tratou da competitividade entre laboratórios farmacêuticos de grandes marcas e genéricos. A autora Caroline Le Goffic ${ }^{7}$ desnuda um cenário jurídico bastante controverso em seu país. De acordo com o texto, os laboratórios de genéricos que exploram as patentes expiradas ficam em desvantagem quando lançam seu medicamento, pois, apesar de a patente não existir mais, o monopólio sobre a marca do medicamento de referência permanece e pode ser renovado infinitamente. Dessa forma, mesmo sendo medicamentos semelhantes aos das grandes indústrias, os genéricos não possuem a marca do primeiro laboratório. A partir dessa situação, existe uma tendência no Judiciário francês de prever certas exceções em relação ao monopólio de titularidade da marca. De acordo com a autora, todas as manobras legislativas expostas para estabelecimento de um "equilíbrio concorrencial" mostram que as regras do código francês do consumidor prevalecem sobre as do Código de Propriedade Intelectual, com o objetivo de beneficiar os fabricantes de produtos genéricos e, consequentemente, a saúde pública.

A última incursão francesa, de autoria de Florian $\mathrm{Kastler}^{8}$, trata da evolução dos direitos humanos e suas consequências para a realização de ensaios clínicos na França e na União Europeia. A Lei de Huriet, de 1988, versa sobre definições,

\footnotetext{
${ }^{5}$ PEIGNÉ, Jérôme. op. cit., p. 83.

${ }^{6}$ LAUDE, Anne. Os conflitos de interesse no direito sanitário francês. In: AITH, Fernando; DALLARI, Sueli Gandolfi (Orgs.). op. cit., p. 187-198.

${ }^{7}$ LE GOFFIC, Caroline. Marcas de produtos farmacêticos: campo de batalha entre medicamentos de referência e genéricos. In: AITH, Fernando; DALLARI, Sueli Gandolfi (Orgs.). op. cit., p. 211-228.

${ }^{8}$ KASTLER, Florian. 0 marco regulatório de ensaios clínicos na França e na União Europeia. In: AITH, Fernando; DALLARI, Sueli Gandolfi (Orgs.). op. cit., p. 365-396.
} 
princípios éticos, direitos e obrigações de empresas farmacêuticas e pacientes voluntários na realização de ensaios clínicos em território francês. Considerada um marco regulatório pioneiro, a lei sofreu modificações e atualmente vigora de certa forma incorporada ao novo Regulamento de 2014 da União Europeia. O autor estabelece comparações entre os marcos regulatórios francês e europeu, sendo que este último, apesar de ter se baseado muito no marco francês, inovou substancialmente em suas determinações. Por fim, o autor sugere a elaboração de um marco regulatório brasileiro a respeito de ensaios clínicos e recomenda uma série de medidas para manter a atratividade do mercado brasileiro e um alto nível de proteção do paciente voluntário.

Passando para outro continente, o artigo de K. S. Prasanth ${ }^{9}$ trata da política regulatória de medicamentos na Índia, notadamente em relação às regras para a realização de ensaios clínicos para aprovação de novos fármacos naquele país. Por se tratar de uma nação emergente, realidade partilhada com o Brasil, o autor enumerou semelhanças entre os dois países no tocante a diretrizes legislativas, exploração de licenças compulsórias e desafios futuros na área de saúde pública para ambas as nações.

Uma terceira análise legislativa envolvendo a questão de pesquisas e ensaios clínicos vem dos Estados Unidos. O autor Michael Werner ${ }^{10}$ revela, por meio de um panorama histórico e jurídico de seu país, quais são os mecanismos normativos utilizados pelas agências federais responsáveis a fim de garantir a proteção da dignidade humana de pacientes que se voluntariam para a realização de ensaios clínicos.

Outra contribuição norte-americana para esta obra abordou os medicamentos falsificados e subpadronizados. A partir de um relatório produzido pelo Institute of Medicine (IOM), os autores Lawrence Gostin, Michele Forzley e Joseph Page $^{11}$ analisam questões consideradas importantes a respeito das consequências advindas da comercialização de medicamentos inseguros e as possíveis medidas para reduzir a incidência desses remédios defeituosos no mercado internacional.

Voltando a uma perspectiva brasileira a respeito do tema de regulação, o texto dos autores Diego Coutinho e Nathalia Miziara ${ }^{12}$ traz uma análise crítica a respeito dos mecanismos institucionais de participação social, transparência e accountability no âmbito da Agência Nacional de Vigilância Sanitária, órgão responsável pela regulação geral do setor de saúde no Brasil.

9PRASANTH, K. S. A política regulatória de medicamentos na Índia: perspectivas legais, marco institucional, ensaios clínicos e harmonização. In: AITH, Fernando; DALLARI, Sueli Gandolfi (Orgs.). op. cit., p. 121-154.

${ }^{10}$ WERNER, Michael J. Proteção de sujeitos humanos nos Estados Unidos: um modelo para o Brasil? In: AITH, Fernando; DALLARI, Sueli Gandolfi (Orgs.). op. cit., p. 427-442.

${ }^{11}$ GOSTIN, Lawrence; FORZLEY Michele; PAGE, Joseph A. Uma perspectiva norte-americana sobre medicamentos falsificados e subpadronizados. In: AITH, Fernando; DALLARI, Sueli Gandolfi (Orgs.). op. cit., p. 247276.

${ }^{12}$ COUTINHO, Diogo R; MIZIARA Nathália. Participação social, transparência e accountability na regulação sanitária da ANVISA. In: AITH, Fernando; DALLARI, Sueli Gandolfi (Orgs.). op. cit., p. 305-335. 
Longe de esgotar o assunto, a publicação apresenta conclusões e opiniões de absoluto rigor científico a respeito do tema proposto. Outra característica que se pode destacar é a diversidade de pontos de vista em razão das diferentes nacionalidades dos colaboradores.

Em suma, Regulação de medicamentos no mundo globalizado é uma publicação inovadora, que merece leitura atenta dos interessados, seja pela especificidade conferida aos artigos, seja pela fertilidade que o tema ainda oferece.

\section{Referências}

AITH, Fernando M. A.; CUNHA, Ana Carolina Navarrete M. F. da; CASTELLARO, Felipe Angel B.; SOARES, Darnise Francinne Lopes; DALLARI, Sueli Gandolfi. Política de regulação de drogas e medicamentos no Brasil: panorama normativo e institucional. In: AITH, Fernando; DALLARI, Sueli Gandolfi (Orgs.). Regulação de medicamentos no mundo globalizado. 1. ed. São Paulo: CEPEDISA, 2014. p. 459-556.

COUTINHO, Diogo R; MIZIARA Nathália. Participação social, transparência e accountability na regulação sanitária da ANVISA. In: AITH, Fernando; DALLARI, Sueli Gandolfi (Orgs.). Regulação de medicamentos no mundo globalizado. 1. ed. São Paulo: CEPEDISA, 2014. p. 305-335.

GOSTIN, Lawrence; FORZLEY Michele; PAGE, Joseph A. Uma perspectiva norte-americana sobre medicamentos falsificados e subpadronizados. In: AITH, Fernando; DALLARI, Sueli Gandolfi (Orgs.). Regulação de medicamentos no mundo globalizado. 1. ed. São Paulo: CEPEDISA, 2014. p. 247-276.

KASTLER, Florian. O marco regulatório de ensaios clínicos na França e na União Europeia. In: AITH, Fernando; DALLARI, Sueli Gandolfi (Orgs.). Regulação de medicamentos no mundo globalizado. 1. ed. São Paulo: CEPEDISA, 2014. p. 365-396.

LAUDE, Anne. Os conflitos de interesse no direito sanitário francês. In: AITH, Fernando; DALLARI, Sueli Gandolfi (Orgs.). Regulação de medicamentos no mundo globalizado. 1. ed. São Paulo: CEPEDISA, 2014. p. 187-198.

LE GOFFIC, Caroline. Marcas de produtos farmacêticos: campo de batalha entre medicamentos de referência e genéricos. In: AITH, Fernando; DALLARI, Sueli Gandolfi (Orgs.). Regulação de medicamentos no mundo globalizado. 1. ed. São Paulo: CEPEDISA, 2014. p. 211-228.

LYNGVIG, Jytte. Uma grande abelha que voa ou como o desenvolvimento da Rede Europeia de Regulação de Medicamentos pode inspirar as considerações para reforma do registro de medicamentos no Brasil. In: AITH, Fernando; DALLARI, Sueli Gandolfi (Orgs.). Regulação de medicamentos no mundo globalizado. 1. ed. São Paulo: CEPEDISA, 2014. p. 47-63.

PEIGNÉ, Jérôme. Mudanças no sistema francês de farmacovigilância (monitoramento de medicamentos): a crescente influência do direito da União Europeia. In: AITH, Fernando; DALLARI, Sueli Gandolfi (Orgs.). Regulação de medicamentos no mundo globalizado. 1. ed. São Paulo: CEPEDISA, 2014. p. 81-100. 
Regulação de medicamentos no mundo globalizado

PRASANTH, K. S. A política regulatória de medicamentos na Índia: perspectivas legais, marco institucional, ensaios clínicos e harmonização. In: AITH, Fernando; DALLARI, Sueli Gandolfi (Orgs.). Regulação de medicamentos no mundo globalizado. 1. ed. São Paulo: CEPEDISA, 2014. p. 121-154.

WERNER, Michael J. Proteção de sujeitos humanos nos Estados Unidos: um modelo para o Brasil? In: AITH, Fernando; DALLARI, Sueli Gandolfi (Orgs.). Regulação de medicamentos no mundo globalizado. 1. ed. São Paulo: CEPEDISA, 2014. p. 427-442.

Renata Rothbarth - Advogada especialista em Direito Médico e Hospitalar e Bolsista no Programa de Aprimoramento Profissional em Direito Sanitário e Advocacia em Saúde do Núcleo de Pesquisa em Direito Sanitário da Universidade de São Paulo. São Paulo/SP, Brasil. E-mail: renata.rothbarth@hotmail.com. 